Bryn Mawr College

Scholarship, Research, and Creative Work at Bryn Mawr College

Library Staff Research and Scholarship

Library and Information Technology Services

1996

\title{
Application of PIXE to the study of Renaissance style enamelled gold jewelry
}

\author{
Marianne Weldon \\ Bryn Mawr College, mweldon@brynmawr.edu \\ J. Carlson \\ S. Reedy \\ C. P. Swann
}

Let us know how access to this document benefits you.

Follow this and additional works at: http://repository.brynmawr.edu/lib_pubs

Part of the Art and Materials Conservation Commons

\section{Custom Citation}

Weldon, Marianne, Carlson, J., Reedy, S., Swann, C.P. "Application of PIXE to the study of Renaissance style enameled gold jewelry." Nuclear Instruments and Methods in Physics Research Section B: Beam Interactions with Materials and Atoms Vol. 109/110 (1996) 653-657.

This paper is posted at Scholarship, Research, and Creative Work at Bryn Mawr College. http://repository.brynmawr.edu/lib_pubs/13

For more information, please contact repository@brynmawr.edu. 


\title{
Application of PIXE to the study of Renaissance style enamelled gold jewelry
}

\author{
M. Weldon ${ }^{\text {a }}$ J. Carlson ${ }^{\mathrm{b}}$, S. Reedy ${ }^{\mathrm{c}}$, C.P. Swann ${ }^{\mathrm{d}}$ \\ ${ }^{a}$ The Detroit Institute of Arts, Detroit, MI 48202, USA \\ ${ }^{b}$ The Winterthur Museum, Winterthur, DE 19735, USA \\ ${ }^{c}$ The Art Conservation Program, University of Delaware, Newark, DE 19716, USA \\ ${ }^{d}$ The Bartol Research lnstitut,. University of Delawar.. Newark, DE 19716, USA
}

\begin{abstract}
This study examines and compares three pieces of Renaissance style gold and enamelled jewelry owned by the Walters Art Gallery, Baltimore, MD, USA. These are a 16th century Hat Badge of Adam and Eve, a 19th century Fortitude Pendant and a Diana Pendant presumed to be of the 16th century (The Walters Art Gallery, Jewelry, Ancient to Modern (Viking, New York, 1979)), Ref. [1]. PIXE spectroscopy was applied to examine the elemental composition of the gold and of the enamels. Compositional differences, including the use of post-Renaissance colorants, were found between the enamels in separate regions of each of the three pieces. The modern colorant, chromium, was, in fact, found in all of the pieces and uranium was found in only the Diana Pendant. There are some differences in the gold purity of the three objects; there are significant differences in the solders used even within one object, the Fortitude Pendant.
\end{abstract}

\section{Introduction}

The Renaissance period in Europe (15th to 16th century) was a time of great advancement in almost all aspects of society. This was the consequence of the release of the society from the domination by the church and its hierarchy. Needless to say art of all forms blossomed during this extended period. Jewelry of all types, especially pendants and hat badges, became strong indicators of wealth and prestige. Unfortunately, however, much of the jewelry produced for the elite has been lost or destroyed to recover the gold and gems, and in addition very little of such art work was signed by the artisans. Consequently, the provenance for a great deal of jewelry created during this time is not known and must be conjectured on the basis of the style, the craftsmanship or on the elemental composition of the pigments used in the colorants. This last point is very important in that some elements only became available as colorants for the artisan after a certain specific date in time. In this study we have applied in-air (or helium) PIXE spectroscopy for the analysis of the golds and enamels of three pieces of enamelled gold jewelry. The PIXE technique has the advantages of good spatial resolution, non-destructiveness and good detection limits for the elements from $\mathrm{Na}$ to $\mathrm{Sb}$ and for $\mathrm{Au}$ and $\mathrm{Pb}$.

The question of whether or not these three pieces of jewelry are of the Renaissance period is problematic except for the Fortitude Pendant. Renderings for this pendant are found in the prints and drawings collection of the Victoria and Albert Museum of London, England, and has been classified as a 19th century work of the Aachen goldsmith Reinhold Vasters (1853-1890) [2,3]. However, the provenance of the other two pieces is not documented; the Hat Badge is presumed to have originated during the Renaissance but there is doubt on the early date for the Diana Pendant. Provenancing of these pieces is also made difficult as a consequence of the highly advanced level of goldsmithing during the Renaissance; earlier works could be identified by marks produced by the craftsman tools, whereas the tools used from Renaissance on have changed only slightly [4]. The use of the PIXE technique, therefore, appears to be one of the few ways of setting a time limit on the date of construction.

\section{Elemental analysis}

There is very little reported in the literature with quantitative information on enamelled wares. Henderson et al. [5] have studied the technologies involved in the construction of glass enamel inlays and beads in Europe during the 4th to the 1st centuries B.C. and in the production of Chinese metal and ceramic enamels from the 17th and 18th centuries A.D. Information on Northern Romanesque Medieval enamels appears in a catalogue of the British Museum [6]. However, there appears to be no publications on enamels of the Renaissance period.

True enamels are vitreous coatings fused to, in the case of gold jewelry, the gold backing. The basic glass is relatively soft composed of sand $\left(\mathrm{SiO}_{2}\right)$, lime $(\mathrm{CaO})$, soda $\left(\mathrm{Na}_{2} \mathrm{O}\right)$ or potash $\left(\mathrm{K}_{2} \mathrm{O}\right)$ and red lead $\left(\mathrm{Pb}_{3} \mathrm{O}_{4}\right)$; this latter serves both as an opacifier and to lower the melting temperature of the enamels. The glass as such is called the flux and to this is added the metal oxides to give the desired colors. There are, however, other materials which can result in glazes (such as lead silicate) which can be identified by the lack of the components that result in glasses; these materials, technically, cannot be called enamels. Finally, there can be coatings which are not glazes, that is, they have not be fired at all. Again such materials can be readily identified in not containing any silicon.

The analyses of the PIXE results was performed using the program PIXAN [7] and a number of glass and gold standards. Adjustments were made in the $\mathrm{K}$ and $\mathrm{L}$ line ratios, required because of the $\mathrm{Al}$ filter used in that part of the measurement involving the elements from $\mathrm{Fe}$ upwards. The resulting detection limits for the $\mathrm{Zn}$ in the solders varies from 0.030 to $0.100 \%$ for the $\mathrm{Au}$ content encountered of 17 to $46 \%$ (see Table 1 ). 
The results of some of the PIXE measurements [8,9] are given in Tables 1 and 2. Not all of the elements observed are included; for the cases of the golds and solders, extraneous elements have been removed as contaminants whereas for the enamels only the oxides involved as colorants, opacifiers and different types of glazes are given, and these only for the Hat Badge. The values shown in Table 1 are expressed in atomic weight percent and those in Table 2 as oxides in weight percent. Although no burnishing or polishing of these objects was allowed, the presence of sodium was observed for most of the colorants suggesting that true enamels were being produced.

Table 1

$\mathrm{Au}$ and solder composition (in wt.\%)

$\begin{array}{clllllll}\text { Element: } & \mathrm{Au} & \mathrm{Ag} & \mathrm{Cu} & \mathrm{As} & \mathrm{Pb} & \mathrm{Sn} & \mathrm{Zn} \\ \text { Hat Badge } & & & & & & & \\ \quad \text { Front panel } & 72.03 & 24.15 & 3.21 & 0.24 & - & - & - \\ \text { Back panel } & 71.84 & 26.58 & 2.83 & 0.23 & - & - & - \\ \quad \text { Inner rim } & 77.01 & 19.54 & 2.78 & 0.29 & - & - & - \\ \quad \text { Outer rim } & 66.60 & 28.44 & 4.36 & 0.50 & - & - & - \\ \text { Fortitude Pendant } & & & & & & & \\ \quad \text { Figure } & 74.33 & 18.28 & 6.30 & 0.21 & - & - & 0.79 \\ \quad \text { Front sheet } & 77.30 & 17.24 & 3.97 & 0.18 & - & - & 0.51 \\ \text { Gem mount 1 } & 95.27 & 2.76 & 1.50 & 0.29 & 0.11 & - & - \\ \quad \text { Gem mount 2 } & 73.68 & 21.82 & 5.44 & 0.19 & - & - & - \\ \quad \text { Solder 1 } & 42.45 & 23.00 & 32.20 & 0.13 & - & - & 2.24 \\ \text { Solder 2 } & 45.87 & 30.13 & 8.82 & - & 1.58 & 13.2 & 0.17 \\ \quad \text { Solder 3 } & 18.31 & 6.07 & 5.18 & 0.13 & 0.24 & 68.58 & 1.21 \\ \text { Figure } & & & & & & & \\ \text { Gem mount 1 } & 70.00 & 23.53 & 6.12 & 0.27 & - & - & - \\ \text { Gem mount 2 } & 72.15 & 23.73 & 3.06 & 0.26 & 0.75 & - & - \\ \text { Solder } & 16.98 & 6.75 & 1.81 & 11.96 & 58.30 & 3.62 & -\end{array}$

Table 2

Compositional data for the Hat Badge (in wt.\%). Only oxides showing the differences between the main body and the rim given; additional oxides observed are $\mathrm{AuO}, \mathrm{Ag}_{2} \mathrm{O}, \mathrm{ZnO}, \mathrm{CoO}$ and $\mathrm{MnO}$. Blues were also seen on the rim but not in the body

\begin{tabular}{|c|c|c|c|c|c|c|c|c|}
\hline \multirow{2}{*}{ Red } & & $\mathrm{PbO}$ & $\mathrm{As}_{2} \mathrm{O}_{3}$ & $\mathrm{CuO}$ & $\mathrm{Sb}_{2} \mathrm{O}_{5}$ & $\mathrm{Cr}_{2} \mathrm{O}_{3}$ & $\mathrm{Fe}_{2} \mathrm{O}_{3}$ & $\mathrm{SnO}$ \\
\hline & Center & 1.06 & - & 1.73 & - & - & 0.93 & 2.83 \\
\hline \multirow{5}{*}{ White } & Rim & 15.90 & 1.16 & 3.34 & 5.23 & - & 0.13 & - \\
\hline & & & & & & & & \\
\hline & Center & 13.62 & - & 0.11 & - & - & 0.33 & 47.05 \\
\hline & Rim & 27.35 & 8.42 & 1.62 & 4.28 & 0.01 & 0.19 & - \\
\hline & Repair & 50.31 & - & 0.20 & - & - & 0.41 & - \\
\hline \multicolumn{9}{|l|}{ Green } \\
\hline & Center & 0.64 & - & 38.22 & - & - & 15.99 & - \\
\hline & $\operatorname{Rim}(\operatorname{trans})$ & 5783 & - & 20.64 & - & 0.05 & 0.22 & 7.27 \\
\hline & $\operatorname{Rim}($ opaq) & 30.92 & 9.85 & 5.20 & - & 0.53 & 0.18 & - \\
\hline \multicolumn{9}{|l|}{ Black } \\
\hline & Center & 16.33 & - & 1.93 & - & 0.04 & 19.81 & 39.91 \\
\hline & Rim & 20.68 & - & 8.85 & - & 0.07 & 0.32 & 0.63 \\
\hline
\end{tabular}

\section{Results and discussion}

\subsection{The Hat Badge}

Fig. 1 is a photograph of the face of this Hat Badge and depicts the scene of Adam and Eve in the Garden of Eden. Such badges were popular amongst the gentleman of prominence during the early part of the 16th century. The badge consists of two gold panels, the front being the figurative casting and the back a textured sheet, held together with flanges. Surrounding these panels is a decorative gold rim, attached to the back panel with screws and nuts located under the gem mounts. The six gems are clearly visible in the photograph but the spacing is not regular suggesting the possibility of a repair having been performed. A banner with an inscription surrounds the figures but only the letters "LE" remain as the result, again, of repair work. Essentially all of the 
front panel is enamelled with colors of white, red, green, brown and black; the whites are opaque whereas the others are transparent. The flowers of the outer rim are enamelled in blue, green, white, red and black. Again the whites are opaque as are one each of the blues and greens; the rest are transparent.

Referring to the data of Table 1 it is clear that the gold of the outer rim is of a different purity from that of the inner panels. The results for the enamels as given in Table 2 also show rather different compositions for these two regions. Most important, however, are the differences in the composition of the greens with those of the rim containing $0.5 \%$ chromium; Cr as a colorant was not known to exist until the 19th century [10]; $\mathrm{Cr}$ as an impurity in medieval window glass has been reported to be less than $12 \mathrm{ppm}$ [11]. Other differences relate to the glass matrices of the rim and the panel and to the whites of these two areas. Generally speaking, the glasses of the panel are higher in $\mathrm{Si}, \mathrm{K}$ and $\mathrm{Ca}$ and lower in $\mathrm{Pb}$ than those of the rim and the white of the figures are high in Sn relative to the rim which is high in lead and arsenic. The repair whites of the figures and the banner are clearly not enamels, lacking in the necessary components to form glass and, obviously, were not fired. In conclusion, therefore, it is probable that at least two changes were made for this Hat Badge from the original construction. First, it is suggested that the present outer rim is not the original based on the Au composition and on the composition of the colorants, including a chromium green, which are quite different from the inner panel. Second, the irregular positioning of the gems and on the composition of the whites of the banner and the figure indicate that repair work was performed. The new rim and its floral design were probably done by a first class jeweler whereas the repair work on the main body was not. Although the provenance of this badge is not documented it does appear in most aspects to be of the Renaissance period with subsequent alterations being the result of damage over time.

\subsection{The Fortitude Pendant}

A photograph of the ornamental face of this pendant is presented in Fig. 2. Pendants of this type are large and ornate and may have taken the place of the hat badge as the medium used by jewelers to display their virtuosity. This particular pendant is thought to be a product of the craftsman Reinhold Vasters, as noted earlier, and to represent the allegorical figure of Fortitude. The castings of the mount section appears to be very brittle and have many small cracks and small areas of porosity; the castings of the figure and ornament for the suspension chain do not display such flaws. It is possible that the cracks and porosity are the consequence of a solder repair.

As can be seen from the data of Table 1, there are three very different solders involved with the construction of this pendant; one resembles present day "silver solder", i.e., $\mathrm{Ag}, \mathrm{Cu}$ and $\mathrm{Zn}$ while the other two contain differing amounts of $\mathrm{Pb}$ and $\mathrm{Sn}$. The melting points for these solders vary considerably but most important is the fact that all the temperatures are above the temperature required for enameling. Such high temperatures would destroy any pre-existing enamel, suggesting that the soldering was done first with the possible exception of solder 3. This latter may account for the cracks and porosity cited above. Just why any goldsmith would use so many different solders is not clear; perhaps it is just a matter of what was on hand when the soldering was performed.

Regarding the enamels there are different significant differences in the composition of the colorants used for the different regions. The white of the figure is high in Sn as compared to the mount and ornament. The reds of the figure are also different from those of the mount and ornament. The greens, blues and black do not appear in the figure, but the two blues in the mounts are very different in composition. The green content of $0.21 \%$ places this colorant in the 19th century as pointed out above. Whether these variations are the consequence of the use of different compositions during the construction process or are the result of re-enameling is not clear. A similar study of other works of Vasters would perhaps shed light on this question.

\subsection{The Diana Pendant}

This pendant is shown in the photograph of Fig. 3. The scene is of a statuette of Diana dressed for hunting with her hound at her side. Both sides of this pendant are enamelled with the various components being held together with screws and nuts. The designation as being of the Renaissance period from South Germany has been questioned by Hugh Tait, Deputy Keeper of the Department of Medieval and Later Antiquities at the British Museum [12]. Tait noted on the basis of a visual study that this object looks as if it were mass produced, that the removal of the screws would destroy the enamel and that the appearance is more architectural than three dimensional.

Our own visual examination also suggests other factors: (1) The area of the boots appears to have been re-enamelled either to change the color from the original or as a repair later; the color scheme, however, is in keeping with other representations of Diana. (2) There are areas in which the enamel is full of bubbles; this could be the result of firing without properly packing and drying to remove the air, the presence of impurities or firing below the maturation temperature. (3) The columns beside Diana and the hounds have been extended by the addition of four small pieces of gold joined with a solder the composition of which is given in Table 1. This solder is not of any common variety but would have a reasonably low melting point; the enameling could have preceded the soldering. Just why the columns were lengthened is not known and may have just been a modification by the craftsman. The only record of any restoration of this piece is a note in the exhibition catalogue of the Walters Art Gallery that the three hanging pearls are replacements. 
The analysis of the PIXE data for the white, red, blue and purple enamels of the figures and the framework for these figures are very different in their elemental composition. This framework also contains enamels in black and yellow, the yellow being derived from uranium oxide. In addition, there are three different greens, the dark green of the figure, the light greens of the framework, these being transparent, and an opaque green in the framework. All of these greens are the result of chromium in the pigment. The difference between the compositions of the figures and the background manifests itself primarily in a significantly higher silica and lower lead content for the figures as compared to the background mounts. It is quite possible that the central region containing the figures was constructed before the background and that a higher temperature was used in the enameling. The background enamels could then have been formed without disturbing the enamels of the figures. Since neither chromium or uranium were known to exist as colorants until at least the 19th century it is quite clear that this pendant is not of Renaissance times.

\section{Conclusions}

This study using PIXE spectroscopy demonstrates the capability of this technique in resolving the question of the possible period of construction of antique jewelry. Of the three pieces examined only the Hat Badge could have originated during the

Renaissance era., and even this object underwent significant repairs into the 19th century.

\section{References}

[1] The Walters Art Gallery, Jewellery: Ancient to Modern (Viking, New York, 1979).

[2] Y. Hackenbrook, Metropolitan Museum of Art. J. 19/20 (1986) 163.

[3] M. Sharp Young, Apollo 120 ( 1984) 201.

[4] D.L. Carroll, Archeomaterials 1 (1986) 153.

[5] J. Henderson, N. Wood and M. Tregear, in: Cross-Craft and Cross-Cultural Interactions in Ceramics (American Ceramics Soc., Westerville, OH, 1989) p. 315.

[6] N. Stratford, in: Catalogue of Medieval Enamels in the British Museum, p. 315. Vol. 2 (British Museum Press, 1993).

[7] E. Clayton, Nucl. Instr. and Meth. B 30 (1988) 303.

[8] C.P. Swann, P.E. McGovern and S.J. Fleming, Nucl. Instr. and Meth. B 45 (1990) 311.

[9] C.P. Swann and S.J. Fleming, Scanning Microscopy 2 (1988) 197.

[10] R. Gettens and G. Stout, Painting Materials (Dover, New York (1966) p. 107.

[11] Olin et al., Neutron Activation and Electron Beam Microprobe Study of a XIV Century Austrian Stained Glass Panel, Applicazione Dei Metodi Nuclearri Nelcampodelleopere D'Art (Acadeomia Nazionale Dei Lincei, 1976) p. 99.

[12] Personal communication with: J. Spicer, Curator of Renaissance and Baroque Art, The Walters Art Gallery, Baltimore, MD, USA. 